\title{
Team Process Measurement: A Comparison of Criterion-Related Validity of Teamwork Appraisal Tools
}

\author{
Sayeedul Islam \\ Farmingdale State College \\ Talent Metrics Consulting \\ Jennifer Nieman-Gonder \\ Farmingdale State College \\ David Cassel \\ Hofstra University
}

\begin{abstract}
As organizations compete in an increasingly VUCA environment, performance appraisal processes become more important to their success. This is especially true as teams are implemented in organizations as a tool to make complex decisions. Little work has been done to assess the effectiveness of performance appraisal tools in predicting objective team performance. In the present study, 57 students organized into 19 3-person teams to work on a task. Results indicate that team process measurements were strongly correlated with one another but were not very predictive of objective team performance. Teams that viewed themselves as "real" teams were correlated with task performance. Future research should evaluate other team process measures for their criterion-related validity.
\end{abstract}

Keywords: teams, teamwork, performance appraisal

\section{INTRODUCTION}

Modern organizations function in a VUCA environment and must strive to maintain a competitive edge (Srivastava, Rogers, \& Lettice, 2013). Trends such as a declining and under skilled entry level workforce (Dean, 2017) along with an increasingly competitive talent marketplace require that an advanced human resources function should be maintained to derive the maximum of individual worker productivity (Mondy, Noe, \& Premeaux, 2002; Goldstein \& Ford, 2002). Performance evaluation of employees has become an increasingly important process to organizations despite the pushback against traditional performance appraisal (Bayo-Moriones et al., 2019). Performance appraisal processes are the formalized means of assessing worker performance in comparison to certain established organizational standards (Riggio, 2000) and often serve as a proxy to objective performance evaluation. Performance evaluation and performance feedback represent the two parts of the performance appraisal process. Evaluation represents the assessment of an employee's performance against established standards, while feedback refers to the 
process of providing information to an employee regarding performance level including suggestions for improving future performance (Riggio, 2000).

Performance appraisals are considered one of the most important aspects of human resources and affect a variety of organizational decisions (Cawley, Keeping, \& Levy, 1998). Appraisals have a significant impact on administrative decisions such as compensation, promotions, and individual employee development opportunities (Cleveland, Murphy, \& Williams, 1989). An increasing number of organizations have implemented systems solely for the purpose of individual development and in many cases, performance appraisal is intended to be an instrument for personal development. These systems which if used correctly, should result in positive behavior changes theoretically aggregate to performance improvement within the organization overall (Jansen \& Vloeberghs, 1999; Iqbal et al., 2019).

Despite the use of these systems, measurement remains an issue and the effectiveness of appraisal systems remains an open question (Nieman-Gonder, Metlay, Shapiro, 2018). Organizations often define performance behaviorally and measure using subjective criteria. These ratings are used to provide individuals and teams with feedback. This appraisal method has left researchers with a number of methodological and practical questions the two most important: (1) whether this practice is based on the assumption that the behavioral criteria underlie individual and organizational outcomes and (2) whether the practice of subjective measurement is criterion valid in terms of the relationship between subjective ratings of behaviors and outcome measures.

The goal of performance appraisal is to change an individual's job-related behavior and improve performance outcomes. Thus, the selected behaviors assessed in the appraisal process must be theoretically related to these behavioral outcomes i.e. criterion-related validity. Feedback related to the the evaluation will lead to changes in outcome measures if the behaviors are related to actual job performance (Jones et al., 1993) and this process becomes more complex within the team context. Given the issues in individual performance appraisals, teamwork presents a new challenge to researchers and practitioners alike. The present research will focus on criterion-related validity of team process measures.

Teamwork has become a major part of organizations and has been extensively studied (Kane, 2011; Winsborough, 2018). Sundstrom, DeMeuse, and Futtrell (1990) identified six team development models and since that time researchers have developed over 140 models of team performance (Salas, 2010). The proliferation of team models has not solved the challenge of performance measurement. Some team models focus on task work which has been defined as "what the team is doing" (Marks, Mathieu, \& Zaccaro, 2001) within a team context, whereas other models focus on team processes describing how effectively the team is working with one another and some attempt a more holistic approach (Eaidgah, Abdekhodaee, Najmi, \& Maki, 2018). Numerous measures have been developed to evaluate team performance (Paris, Salas and Cannon-Bowers, 2000; Smart \& Siguaw, 2020). Many measures involve the rating of behaviors or competencies (i.e., collaboration), either at the aggregated-individual or team level. Other techniques involve the rating of team characteristics or processes such as team potency, composition, and interdependence (i.e., Campion et al., 1993; Wageman, et al., 2005). Prewett et al. (2009) presented a comprehensive framework around the criterion performance question. Their findings indicate that mean scores on traits offer similar predictive capabilities as low and high scores. The challenge of parsing individual performance and team performance from one another has continued to challenge researchers and practitioners (Peacock et al., 2007). Organizations require practical, criterion relevant measures and little work has been done to compare across measures to show these measures' differential effectiveness in predicting objective team performance.

The present study serves as an exploratory examination of the criterion relevance of several researchbased team process measurement techniques and a comparison across these measures. The researchers hope to address the following research questions:

Research Question 1: Are self-reported measures of team performance related to objective team performance? 
Research Question 2: Which self-reported measure of team performance predicts objective team performance most effectively?

Research Question 3: How strongly intercorrelated are self-report measures of team performance?

\section{METHOD}

\section{Participants}

60 undergraduate psychology students enrolled at a private Northeastern University participated in the study. Participants were recruited through a psychology subject pool. Based on availability, participants were assigned to three-person teams. The study involved 20 teams of three participants each.

\section{Procedure}

Participants were organized in teams of three and completed the merit bonus activity adapted from Marcic (1989). A portion of this activity can be found in Appendix A. This task has been used in several studies involving teamwork (Saavedra, Early, and Van Dyne, 1993). To perform the task, each team member assumed the roles of three mid-level managers at ABC Corporation. Each participant was named as the manager of one of three departments (customer service, technology, or sales) with five direct reports. As part of the annual employee review process, the team was asked to allocate a $\$ 15,000$ bonus pool evenly among the three departments. Thus, each department manager has $\$ 5,000$ to allocate among the five employees in their respective department. To accomplish this task, the team members provided a recommendation for the percent of his/her bonus pool to allocate to each employee in the department (i.e., $10 \%=\$ 500$ ). The percent value for each employee can range from $0 \%$ to $100 \%$ but the full bonus pool had to be allocated. Each team was provided with an organizational chart and an employee profile sheet, documenting information about each employee including his/her title, salary, annual performance rating, age, family status, and qualitative performance comments.

This task was chosen to satisfy two requirements: (1) an optimal solution could be calculated by those with knowledge in the HR field, providing a standard of comparison which can be used to calculate an objective measure of the accuracy of performance, and (2) the scoring procedure maximizes the variance of the dependent measure; for example, this scoring procedure results in more variability than a task in which the solution is either right or wrong (0 or 1$)$.

During the teamwork session, participants completed a team-based ice-breaker activity in order increase familiarity and communication among team members. Upon completion of the icebreaker, teams were given instructions for the Merit Bonus Activity. Team members were asked to imagine themselves as the heads of different departments and to review the relevant employee information to familiarize themselves with the employees eligible for a bonus. They were asked to discuss their strategy for determining how bonuses will be allocated among employees. When each member completed his/her allocation, the team revealed their allocation and combined the results from each department. Upon completion of the task, the participants completed the team evaluation measures.

\section{Performance}

Team performance was measured using the accuracy of the team's decision. Accuracy was calculated by comparing the team's allocation decision with an optimal solution, provided by an 'expert team'. The expert team was comprised of three graduate students enrolled in an Applied Organizational Psychology doctoral program each with practical experience in the Human Resources field. The team allocation decisions for each employee were compared to the optimal allocation, provided by the expert team, and the absolute value of the difference between allocations will be calculated. For example, if a team allocated a $15 \%$ bonus to Employee A and the expert team allocated 25\% to Employee A, the absolute difference would be $10 \%$. Absolute difference scores were calculated for each employee and then summed to determine a team performance score. Higher scores therefore indicate less accuracy than lower scores, with a perfect allocation yielding an accuracy score of 0 . 


\section{Rating Forms}

Upon completion of the bonus allocation task, each team member completed several team evaluation measures including (1) an aggregated individual-level competency-based evaluation; (2) a team-level competency-based evaluation; and (3) a team process-based evaluation.

\section{Competency Based Evaluation}

The competency-based evaluation measure was adapted from McGourty's (2001) Team Developer® program. The program organizes a total of 50 behavioral items under four-dimension headings: collaboration, communication, decision-making, and self-management. The software was developed to enable students to rate team members on behaviors essential to team performance and the value of this program in assessing team behaviors has been cited by several researchers (Dominick et al., 1997; Seat \& McAnear, 2001; Saavedra \& Kwun, 1993). To cut down the list of behaviors, the three doctoral students who served as the 'expert team' were provided with the list of 50 behavioral statements. The students were asked to rate each behavioral item in terms of its importance for success in the bonus allocation task as well as to eliminate items that could not be assessed during the task. Behaviors with an importance rating greater than 4.0 (on a scale of 5) were included in the rating form. The final rating form included 18 behavioral items under the competency heading of communication, collaboration, decision making, and selfmanagement. Participants in the experiment rated team performance using a quality scale ranging from 1 - Inadequate to 7 - Excellent.

In the first method of evaluation, team members were asked to provide a self-rating and a rating for every other team member on the 18 behavioral items included in the competency-based measure. Individual ratings were aggregated to yield an aggregated individual-level team competency rating. In the second method of evaluation, team members will be asked to provide one rating for the team as a whole on the 18 behavioral items included in competency-based measure which will serve as the team-level competency rating.

\section{Team Process Evaluation}

The team process evaluation measure was adapted from Wageman \& Hackman's Team Diagnostic Survey (2005), Campion (1993), and McGourty (2001). Each measure consists of several team processes (i.e., participation, workload sharing, quality of team interaction) evaluated with several items. To reduce the number of team processes evaluated in the present study, we removed redundant and irrelevant items. For example, items in the Team Diagnostic Survey include dimensions on Available Expert Coaching. However, there was no coaching involved in this study. In addition to relevance, redundancy was also considered. For example, group size was measured in the Team Diagnostic Survey and thus the single dimension in the Campion Work Group Characteristic measure was removed for the sake of brevity. The resultant measure consists of 17 team processes evaluated using 88 items. An average of these ratings served as the team process evaluation. A sample item from the Campion measure is "As a member of a team, I have real say in how the team carries out its work", a sample item from the Team Diagnostic Measure is "This team is larger than it needs to be." A sample item from the McGourty measure is "Gave specific and constructive feedback to others"

Each team's objective performance on the task was calculated as the accuracy of the team's decision compared to the optimal solution. Upon completion of the task, participants evaluated their team's performance using three different rating evaluation methods: (1) aggregated individual-level competencybased ratings, (2) team-level competency-based ratings, and (3) team process ratings. The criterion relevance of each evaluation method will be calculated by correlating the team's ratings to their objective accuracy score. Higher correlations indicated greater relevance, suggesting that the team's ratings are good predictors of objective performance. 


\section{RESULTS}

One team was excluded from analyses due to an extreme Merit Bonus Activity decision accuracy score. Descriptive statistics for the final sample's $(N=19)$ objective and self-reported team performance criteria can be found in Table 1. Pairwise Pearson correlation coefficients were computed to explore Research Question 1 by examining the relationships between decision accuracy and self-reported team criteria. Of the self-report measures, only the real team subscale of the TDS was significantly related to decision accuracy. As can be seen in Table 2, the real team subscale exhibited a positive relationship with decision accuracy, $r=.47, p<.05$, suggesting that the more teams are perceived as stable and have clearly defined boundaries, the more likely they are to perform well.

To explore Research Question 2, a multiple linear regression analysis was conducted to test if the TDS real team subscale and any other subjective indicators of team performance significantly predicted decision accuracy. For model 1, the TDS real team subscale significantly predicted decision accuracy, $\beta=21.72$, $t(17)=2.18, p<.05$, explaining $22 \%$ of the variance, $R^{2}=.22, F(1,17)=4.74, p<.05$. The remaining selfreport team performance measures were entered into the regression equation using the stepwise method. Of the measures, the WGS participation subscale was retained alongside the TDS real team subscale. Model 2 explained $45 \%$ of the variance in decision accuracy, $R^{2}=.45, F(2,16)=6.51, p<.01$, with a significant increase in explained variance over model $1, R^{2}$ change $=.23, F$ change $(1,16)=6.70, p<.05$. The TDS real team subscale significantly, positively predicted decision accuracy, $\beta=30.46, t(16)=2.28, p<.01$, while the WGS participation subscale significantly, negatively predicted decision accuracy, $\beta=-24.74$, $t(16)=-2.60, p<.05$.

Research Question 3 was explored by computing multiple Pearson correlation coefficients to examine the relationships among self-report team performance measures. Team-level BRS scores were significantly related to individual-aggregated BRS scores, $r=.73, p<.001$, indicating a strong, positive relationship between the two measurement methods. However, while individual-aggregated BRS scores were significantly related to the WGC composite, $r=.57, p=.01$, and the TDS composite, $r=.53, p<.05$, teamlevel BRS scores were only significantly related to the TDS composite, $r=.51, p<.05$, with no significant relationship to the WGC composite, $r=.38, p=.11$.

Relationships between significant predictors of decision accuracy and other self-report measures were examined. The TDS real team subscale was significantly related to BRS communication (individualaggregated; $r=.49, p<.05)$, TDS diversity $(r=.62, p<.01)$, and TDS strategy $(r=.50, p<.05)$. The WGC participation subscale was significantly related to BRS collaboration (individual-aggregated; $r=.52, p<$ .05 ), BRS communication (individual-aggregated; $r=.53, p<.05$ ), BRS decision-making (individualaggregated; $r=.48, p<.05$ ), BRS self-management (individual-aggregated; $r=.54, p<.05$ ), WGC preference for group work $(r=.53, p<.05)$, TDS diversity $(r=.50, p<.05)$, TDS effort $(r=.61, p<.01)$, TDS processes criteria for team effectiveness $(r=.53, p<.05)$, and TDS interpersonal processes $(r=.54$, $p<.05)$.

Table 3 displays analyses that examined the criterion relevance of each measure by comparing overall ratings to team performance accuracy. Correlational results revealed no significant relationships indicating low criterion relevance. An analysis of subscales revealed a significant correlation $(r=.47)$ between ratings of a real team (from the TDS) and team performance suggesting that bounded, stable teams perform better than those with ambiguous or fluctuating membership.

Table 4 and 5 display the results of a comparison between overall ratings on the three measures. While these measures are often considered conceptually distinct, significant correlations were found between ratings on all three measures. For instance, aggregated individual ratings were strongly related to ratings of the team as a whole $(\mathrm{r}=.75)$ and the team characteristic/process measure $(\mathrm{r}=.60)$. A comparison across subscales revealed several significant relationships. As an example, the TDS diversity subscale was found to be highly correlated with ratings of communication, collaboration, decision making, and selfmanagement suggesting that team members perceive diverse teams as more effective than homogeneous teams. Table 6 contains correlations between the accuracy measure and the team diagnostic measures. 
TABLE 1

DESCRIPTIVE STATISTICS FOR OBJECTIVE and SELF-REPORTED TEAM CRITERIA

\begin{tabular}{lrrrr}
\hline Variable & Mean & \multicolumn{1}{c}{ SD } & Minimum & Maximum \\
\hline Merit bonus activity decision accuracy & 60.79 & 19.08 & 32.00 & 92.00 \\
BRS collaboration (individual) & 5.82 & .69 & 3.83 & 6.78 \\
BRS communication (individual) & 5.61 & .54 & 4.07 & 6.27 \\
BRS decision making (individual) & 5.53 & .65 & 3.84 & 6.31 \\
BRS self-management (individual) & 5.74 & .74 & 3.52 & 6.59 \\
BRS composite (individual) & 5.66 & .63 & 3.85 & 6.39 \\
BRS collaboration (team) & 6.08 & .66 & 5.08 & 7.00 \\
BRS communication (team) & 5.96 & .49 & 5.07 & 6.60 \\
BRS decision making (team) & 5.83 & .60 & 4.47 & 6.53 \\
BRS self-management (team) & 5.88 & .67 & 4.67 & 6.78 \\
BRS composite (team) & 5.93 & .56 & 4.86 & 6.65 \\
WGC participation & 4.25 & .40 & 3.22 & 5.00 \\
WGC pref. for group work & 3.53 & .56 & 2.56 & 4.22 \\
WGC team potency & 3.79 & .47 & 2.67 & 4.56 \\
WGC composite & 3.86 & .38 & 3.11 & 4.56 \\
TDS real team & 3.64 & .41 & 2.89 & 4.44 \\
TDS compelling direction & 3.20 & .33 & 2.44 & 3.78 \\
TDS diversity & 3.77 & .55 & 2.56 & 4.78 \\
TDS effort & 3.57 & .51 & 2.56 & 4.67 \\
TDS strategy & 3.80 & .51 & 2.56 & 4.78 \\
TDS knowledge and skill & 3.69 & .44 & 3.00 & 4.67 \\
TDS process criteria for team effectiveness & 3.69 & .42 & 2.75 & 4.63 \\
TDS interpersonal processes & 4.04 & .37 & 2.90 & 4.62 \\
TDS composite & 3.68 & .33 & 2.96 & 4.41 \\
\hline
\end{tabular}

TABLE 2

PAIRWISE PEARSON CORRELATIONS

\begin{tabular}{lcc}
\hline Pair & Pearson's & $\mathrm{p}$ \\
\hline Accuracy - BRS collaboration (individual aggregate) & -.12 & .61 \\
Accuracy - BRS communication (individual aggregate) & -.11 & .64 \\
Accuracy - BRS decision making (individual aggregate) & -.21 & .39 \\
Accuracy - BRS self-management (individual aggregate) & -.18 & .46 \\
Accuracy - BRS composite (individual aggregate) & -.16 & .50 \\
Accuracy - BRS collaboration (team) & -.12 & .64 \\
Accuracy - BRS communication (team) & -.15 & .54 \\
Accuracy - BRS decision making (team) & -.30 & .21 \\
Accuracy - BRS self-management (team) & -.20 & .42 \\
Accuracy - BRS composite (team) & -.21 & .40 \\
Accuracy - WGC participation & -.28 & .25 \\
Accuracy - WGC preference for group work & -.01 & .97 \\
Accuracy - WGC team potency & -.17 & .48 \\
Accuracy - WGC composite & &
\end{tabular}




\begin{tabular}{lrc}
\hline Pair & Pearson's $\mathrm{p}$ \\
\hline Accuracy - TDS real team & $.47 *$ & .04 \\
Accuracy - TDS compelling direction & -.37 & .12 \\
Accuracy - TDS diversity & .10 & .70 \\
Accuracy - TDS effort & -.12 & .63 \\
Accuracy - TDS strategy & .29 & .23 \\
Accuracy - TDS knowledge and skill & .00 & .99 \\
Accuracy - TDS process criteria for team effectiveness & .08 & .75 \\
Accuracy - TDS interpersonal processes & .09 & .72 \\
Accuracy - TDS composite & & \\
$* \mathrm{p}<.05, * * \mathrm{p}<.01, * * * \mathrm{p}<.001$ & &
\end{tabular}

TABLE 3

CORRELATIONS BETWEEN CAMPION AND BEHAVIORALLY BASED MEASURES

\begin{tabular}{llll}
\hline Campion Measure & Accuracy & Collaboration & Communication \\
\hline Participation & .278 & $.522^{*}$ & $.528^{*}$ \\
Preference & .010 & $.494^{*}$ & $.520^{*}$ \\
Potency & .174 & .240 & .294
\end{tabular}




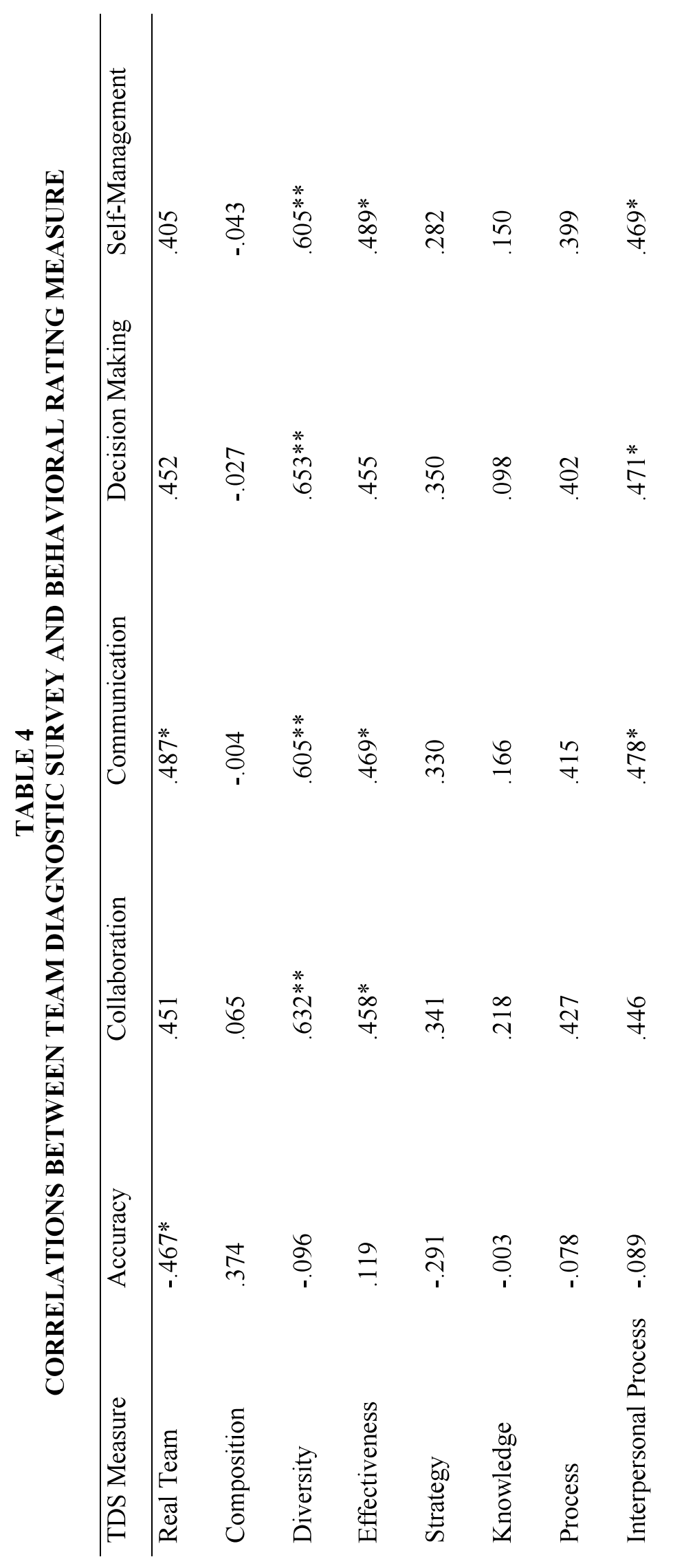


TABLE 5

CORRELATIONS BETWEEN TEAM DIAGNOSTIC SURVEY AND CAMPION MEASURE

\begin{tabular}{llll}
\hline TDS Measure & Campion Participation & Campion Preference & Campion Potency \\
\hline Real Team & .364 & .363 & .197 \\
Composition & .025 & .176 & .126 \\
Diversity & $.493^{*}$ & $.497^{*}$ & $.634^{* *}$ \\
Effectiveness & $.607^{* *}$ & $.588^{* *}$ & $.701^{* *}$ \\
Strategy & .317 & $.500^{*}$ & $.627^{* *}$ \\
Knowledge & .413 & .306 & $.527^{*}$ \\
Process & $.527^{*}$ & $.576^{* *}$ & $.752^{*}$ \\
Interpersonal Process & $.544^{*}$ & .354 & $.636^{* *}$
\end{tabular}

TABLE 6

PAIRWISE CORRELATIONS AT THE TEAM LEVEL

Pearson Correlations

\begin{tabular}{lrc}
\hline & Pearson's r & p \\
\hline Accuracy - BRS collaboration (aggregated) & 0.124 & 0.612 \\
Accuracy - BRS communication (aggregated) & 0.113 & 0.644 \\
Accuracy - BRS decision making (aggregated) & 0.210 & 0.389 \\
Accuracy - BRS self-management (aggregated) & 0.179 & 0.463 \\
Accuracy - BRS composite (aggregated) & 0.164 & 0.503 \\
Accuracy - BRS collaboration (team) & 0.116 & 0.635 \\
Accuracy - BRS communication (team) & 0.150 & 0.541 \\
Accuracy - BRS decision making (team) & 0.302 & 0.210 \\
Accuracy - BRS self-management (team) & 0.196 & 0.420 \\
Accuracy - BRS composite (team) & 0.206 & 0.397 \\
Accuracy - WGC participation & 0.278 & 0.249 \\
Accuracy - WGC preference for group work & 0.010 & 0.969 \\
Accuracy - WGC team potency & 0.174 & 0.477 \\
Accuracy - TDS real team & $-0.467 *$ & 0.044 \\
Accuracy - TDS diversity & -0.096 & 0.695 \\
Accuracy - TDS effort & 0.119 & 0.629 \\
Accuracy - TDS strategy & -0.291 & 0.226 \\
Accuracy - TDS knowledge and skill & -0.003 & 0.990 \\
Accuracy - TDS process criteria for team effectiveness & -0.078 & 0.751 \\
Accuracy - TDS interpersonal processes & -0.089 & 0.718 \\
Accuracy - TDS compelling direction & 0.374 & 0.115 \\
\hline * p $<.05, * * p<.01$, ** p $<.001$ & &
\end{tabular}

\section{DISCUSSION}

The present study served as an exploratory examination of the criterion relevance of and relationship between several measures of team performance. Contrary to expectations, results did not support the criterion relevance of these measures. However, results did reveal several significant relationships among the overall measures as well as the subscales. One of the key issues that the present research was able to highlight is the strong intercorrelation between typical process measures and team ratings. One of the chief 
complaints about performance appraisal is their lack of relevance to actual work (Fletcher, 2001). The present findings seem to indicate that team process measurement is not enough to predict objective team performance and continues to expand the performance appraisal research focusing on sources of performance appraisal data (Facetau \& Craig, 2001).

Organizations continue to struggle to measure team performance and it appears process measurement by itself may not be enough to define team performance. Performance management systems continue to disappoint both employees and managers who use these systems (Cappelli \& Tavis, 2016). The authors of this paper would like to suggest that team process measures may best be used to debrief performance after the fact. As more organizations move to project-based work, performance managers can conduct effective intervention by maximizing the value of team process measures. The strong correlations between these measures indicate some construct validity.

These potential interventions do not solve the challenge of measuring team versus individual performance. Differentiating team and individual performance cannot simply be solved by using averages or ratings forms. Organizations should use both objective and subjective criteria in the development of performance appraisal processes. Team and individual performance indicators should be clearly defined rather than the more generic measures that were used in the current research. Ultimately, managers must decide on the most effective indicators of team performance and use team process measures to manage teams' interactions effectively.

The most intriguing finding from the present study is that teams that viewed themselves as "real" teams predicted task performance. This finding seems to indicate that individuals who view themselves as members of the team are able to perform more effectively or that their actions lead to variance in performance outcomes. This is an intriguing finding and should be further studied by researchers interested in group processes. The stronger intercorrelations between the behavioral rating and the team process measures are also encouraging for managers looking to find effective tools to measure performance. These findings seem to indicate that perceptions of both behaviors and processes overlap. The criterion-related findings also indicate that some of these measures predict some objective outcomes.

\section{Implications for Practice}

These findings are encouraging for anyone who has to manage teams or groups of employees. The present study indicates that team process measures are convergently related to one another and seem to be assessing the same types of behaviors. Moreover, if managers wish to assess performance effectively at least on the subjective level, these measures have shown their worth. However, managers should be mindful of using both objective and subjective criteria evaluate team processes. In order to effectively manage team processes, managers must use effective process measures and tie them to objective criteria to develop team functioning (Curphy, 2012; Winsborough, 2018).

\section{Limitations and Future Research}

The present research has some limitations that should be addressed in future research. First, the activity used in this study was a simulation of a human resources function in an organization. While the activity allowed teams of students to simulate the work of an actual organization future research should try to review project decision effectiveness among work teams involving professionals. A student sample using a simulated activity can provide some initial evidence, but the lack of ecological validity is a concern. At best, the present study provides an understanding of ad hoc or short-term project teams maybe measured using team process tools.

A larger sample size would also increase the efficacy of performance appraisal research. The 20 teams used in the study were appropriate for an exploratory comparison of performance appraisal tools, but teams research requires a much larger sample size for statistical significance (Salas, Cooke, \& Rosen, 2008). Despite the limitations of real performance data, a large sample size of organizational data would provide invaluable insights regarding team and individual performance (Adler, Campion, Colquitt Grubb, OllanderKrane \& Pulakos, 2016). 
The present study was also unable to assess the effect of feedback. While the authors acknowledge the importance of feedback in the evaluation process the experimental design did not allow for the assessment of the effect of feedback. Future research should continue to review the effectiveness of feedback interventions on performance improvement.

\section{CONCLUSION}

The present research represents an incremental step forward in organizational scientists' understanding of the construct of individual and team performance. While performance management and measurement are important factors in organizations, greater focus must be made on utilizing team performance measures effectively to manage teams. In order to effectively move academics and practitioners' understanding of team performance forward, researchers and practitioners must heed the call of early researchers and define performance and measurement tools effectively specifically for the team environment (Natale, Libertella, \& Rothschild, 1995).

\section{REFERENCES}

Adler, S., Campion, M., Colquitt, A., Grubb, A., Murphy, K., Ollander-Krane, R., \& Pulakos, E.D. (2016). Getting rid of performance Ratings: Genius or folly? A debate. Industrial and Organizational Psychology, 9(2), 219-252.

Akella, D. (2013). Creating Successful Teams. Organization Management Journal, 10(3), 208-208.

Bayo-Moriones, A., Galdon-Sanchez, J.E., \& Martinez-de-Morentin, S. (2019). Performance Appraisal: Dimensions and Determinants. The International Journal of Human Resource Management, pp. $1-32$.

Campion, M.A., Papper, E.M., \& Medsker, G.J. (1996). Relations between work team characteristics and effectiveness: A replication and extension. Personnel psychology, 49(2), 429-452.

Cappelli, P., \& Tavis, A. (2016). The performance management revolution. Harvard Business Review, 94(10), 58-67.

Cawley, B.D., Keeping, L.M., \& Levy, P.E. (1998). Participation in the performance appraisal process and employee reactions: A meta-analytic review of field investigations. Journal of Applied Psychology, 83, 615-633.

Cleveland, J.N., Murphy, K.R., \& Williams, R.E. (1989). Multiple uses of performance appraisal: prevalence and correlates. Journal of Applied Psychology, 74(1), 130-135.

Curphy, G. (2012). The Rocket Model: Practical Advice for Building High-Performing Teams.

Dean, S.A. (2019). Soft skills needed for the 21 st century workforce. International Journal of Applied Management and Technology, 18(1). Retrieved from https://scholarworks.waldenu.edu/ijamt/vol18/iss1/5/

Dominick, P.G., Reilly, R.R., \& McGourty, J.W. (1997). The effects of peer feedback on team member behavior. Group and Organization Management, 22, 508-520.

Druskat, V.U., \& Kayes, D.C. (2000). Learning versus performance in short-term project teams. Small group research, 31(3), 328-353.

Eaidgah, Y., Abdekhodaee, A., Najmi, M., \& Arab Maki, A. (2018). Holistic performance management of virtual teams in third-party logistics environments. Team Performance Management: An International Journal, 24(3/4), 186-202.

Facteau, J.D., \& Craig, S.B. (2001). Are performance appraisal ratings from different rating sources comparable? Journal of Applied Psychology, 86(2), 215.

Fletcher, C. (2001). Performance appraisal and management: The developing research agenda. Journal of Occupational and organizational Psychology, 74(4), 473-487.

Goldstein, I.L., \& Ford, J.K. (2002). Training in organizations: Needs assessment, development, and evaluation. Wadsworth/Thomson Learning. 
Iqbal, M.Z., Akbar, S., Budhwar, P., \& Shah, S.Z.A. (2019). Effectiveness of performance appraisal: Evidence on the utilization criteria. Journal of Business Research, 101, 285-299.

Jansen, P., \& Vloeberghs, D. (1999). Multirater feedback methods: Personal and organizational implications. Journal of Managerial Psychology, 14, 455-476.

Jones, S.D., Buerkle, M., Hall, A., Rupp, L., \& Matt, G. (1993). Work group performance measurement and feedback. Group and Organizational Management, 18(3), 269-291.

Kane, K. (2011). Revisiting the behavioral matrix for leadership and team development. Organization Management Journal, 8(1), 23-30.

Marks, M.A., Mathieu, J.E., \& Zaccaro, S.J. (2001). A temporally based framework and taxonomy of team processes. Academy of management review, 26(3), 356-376.

McGourty, J. (2001). Team Developer ${ }^{\circledR}$ Software Program.

Mondy, R.W., Noe, R., \& Premeaux, S.R. (2002). Type Z organization: Stability in the midst of mobility. Human Resource Management, 308

Natale, S. M., Libertella, A. F., \& Rothschild, B. (1995). Team performance management. Team Performance Management: An International Journal, 1(2), 6-13.

Nieman-Gonder, J., Metlay, W., Shapiro, T. (2018) Testing Assumptions: Can Performance Rating Feedback Result in Objective Performance Improvements? Journal of Management and Innovation, 4(2), 1-31

Paris, C.R., Salas, E., \& Cannon-Bowers, J.A. (2000). Teamwork in multi-person systems: A Review and Analysis. Ergonomics, 43(8), 1052-1075.

Peacock, S.E., Denise Lopez, P., \& Sukal, M.F. (2007). Individual Incentives versus Team Performance: Lessons from a Game of Charades. Organization Management Journal, 4(1), 54-68.

Pineda, R.C., \& Lerner, L.D. (2006). Goal attainment, satisfaction and learning from teamwork. Team Performance Management: An International Journal, 12(5/6), 182-191.

Prewett, M.S., Walvoord, A.A., Stilson, F.R., Rossi, M.E., \& Brannick, M.T. (2009). The team personality-team performance relationship revisited: The impact of criterion choice, pattern of workflow, and method of aggregation. Human Performance, 22(4), 273-296.

Riggio, R.E. (2000). Evaluating employee performance. In Introduction to Industrial/Organizational Psychology, $3^{\text {rd }}$ Edition. Upper Saddle River, New Jersey: Prentice Hall.

Rossi, M.E. (2008). The development and validation of the comprehensive team Interdependence scale. Graduate Theses and Dissertations. Retrieved from http://scholarcommons. usf.edu/etd/481

Saavedra, R., \& Kwun, S.K. (1993). Peer evaluation in self-managing work groups. Journal of Applied Psychology, 78(3), 450-462.

Salas, E., Cooke, N.J., \& Rosen, M.A. (2008). On teams, teamwork, and team performance: Discoveries and developments. Human factors, 50(3), 540-547.

Salas, E., Dickinson, T.L., Converse, S.A., \& Tannenbaum, S.I. (1992). Toward an understanding of team performance and training. In R. W. Swezey \& E. Salas (Eds.), Teams: Their training and performance (pp. 3-29). Westport, CT, US: Ablex Publishing.

Seat, E., \& McAnear, P. (2001). Administering, scoring, and debriefing team developer. Presented at the $31^{\text {st }}$ ASEE/IEEE Frontiers in Education Conference.

Swart, W., \& Siguaw, J.A. (2020). The Transformational Impact of Intense Virtual Teamwork Experiences on Team Member Psychometrics: An Exploratory Study. American Journal of Management, 20(1).

Srivastava, M., Rogers, H., \& Lettice, F. (2013). Team performance management: past, current and future trends. Team Performance Management, 19(7/8), 352-362.

Sundstrom, E., McIntyre, M., Halfhill, T., \& Richards, H. (2000). Work Groups: From the Hawthorne studies to work teams of the 1990s and beyond. Group Dynamics: Theory, Research, and Practice, 4(1), 44.

Wageman, R., Hackman, J. R., \& Lehman, E. (2005). Team diagnostic survey: Development of an instrument. The Journal of Applied Behavioral Science, 41(4), 373-398.

Winsborough, D. (2018). The Rise of Teams at Work. People \& Strategy, 41(2), 9-11. 


\section{APPENDIX A}

\section{Situation}

Your team is comprised of three mid-level managers at the ABC Corporation. Manager A is responsible for 5 employees in the sales division. Manager B is responsible for 5 employees in the customer service division. Manager $\mathrm{C}$ is responsible for 5 employees in the technology division. You recently completed the first part of an annual review process during which each member of your team rated his/her employees' performance as (1) exceeds expectations, (2) meets expectations, or (3) below expectations. For the second part of the annual review process, the management team is tasked with allocating a yearly bonus to employees.

The corporation has a $\$ 15,000$ bonus pool to be distributed evenly among departments. Thus, as department managers, you will each receive $\$ 5,000$ to distribute to the employees in your respective departments. Your senior manager has asked that your team make a recommendation for the percent of the bonus pool to be allocated to each of the employees. You cannot limit or exceed the $\$ 5,000$ bonus pool for each department and therefore the percentages should add up to $100 \%$. Your senior manager will review your recommendations and make a final decision.

\section{ANNUAL BONUS ALLOCATION FORM}

\begin{tabular}{|c|c|}
\hline \multicolumn{2}{|c|}{ SALES DEPARTMENT: MANAGER A } \\
\hline & $\%$ OF $\$ 5,000$ BONUS POOL \\
\hline Alice Adams & $\%$ \\
\hline Bob Burns & $\%$ \\
\hline Charlene Carlson & $\%$ \\
\hline Dan Dunn & $\%$ \\
\hline \multirow[t]{2}{*}{ Ed Enders } & $\%$ \\
\hline & TOTAL $=100 \%$ \\
\hline \multicolumn{2}{|c|}{ CUSTOMER SERVICE DEPARTMENT: MANAGER B } \\
\hline & $\%$ OF $\$ 5,000$ BONUS POOL \\
\hline Fran Fox & $\%$ \\
\hline Gus Groom & $\%$ \\
\hline Harry Hall & $\%$ \\
\hline Irene Illman & $\%$ \\
\hline \multirow[t]{2}{*}{ John Janis } & $\%$ \\
\hline & TOTAL $=100 \%$ \\
\hline \multicolumn{2}{|c|}{ TECHNOLOGY DEPARTMENT: MANAGER C } \\
\hline & $\%$ OF $\$ 5,000$ BONUS POOL \\
\hline Karen Kittson & $\%$ \\
\hline Larry Lowman & $\%$ \\
\hline Mary Masters & $\%$ \\
\hline Nicolas Newman & $\%$ \\
\hline \multirow[t]{2}{*}{ Oscar Oswald } & $\%$ \\
\hline & $T O T A L=100 \%$ \\
\hline
\end{tabular}


ABC CORPORATION: ORGANIZATIONAL CHART

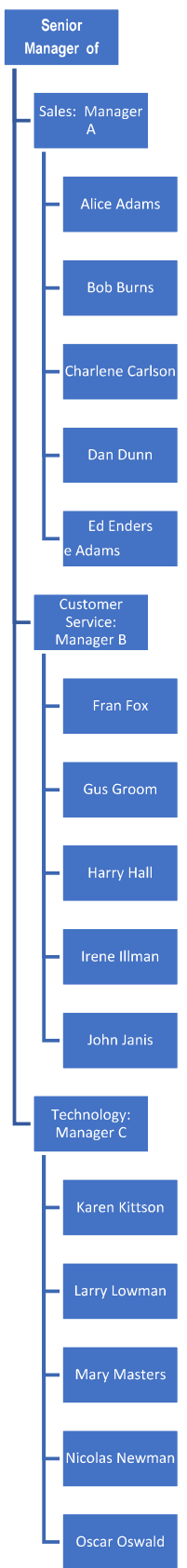




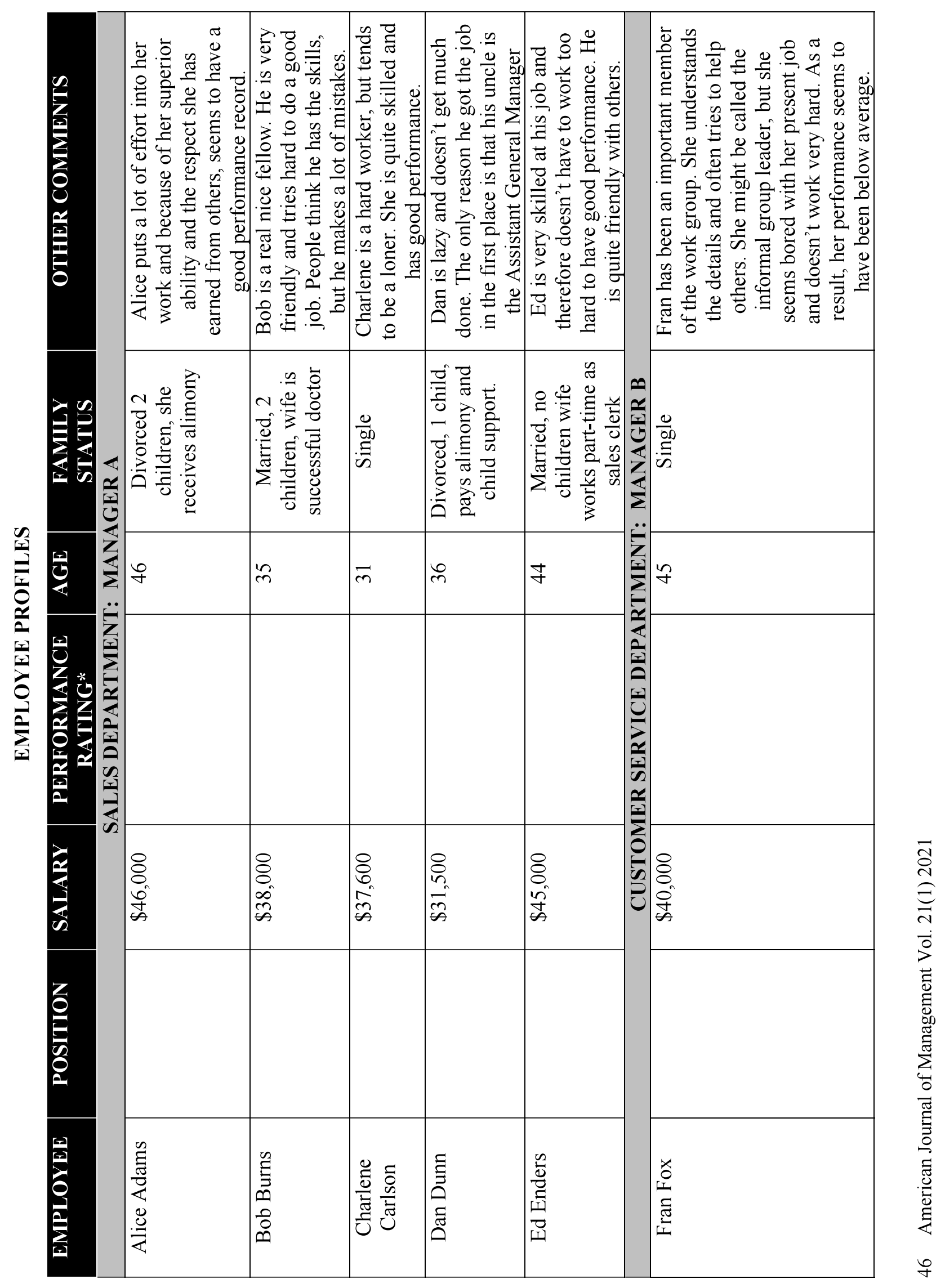




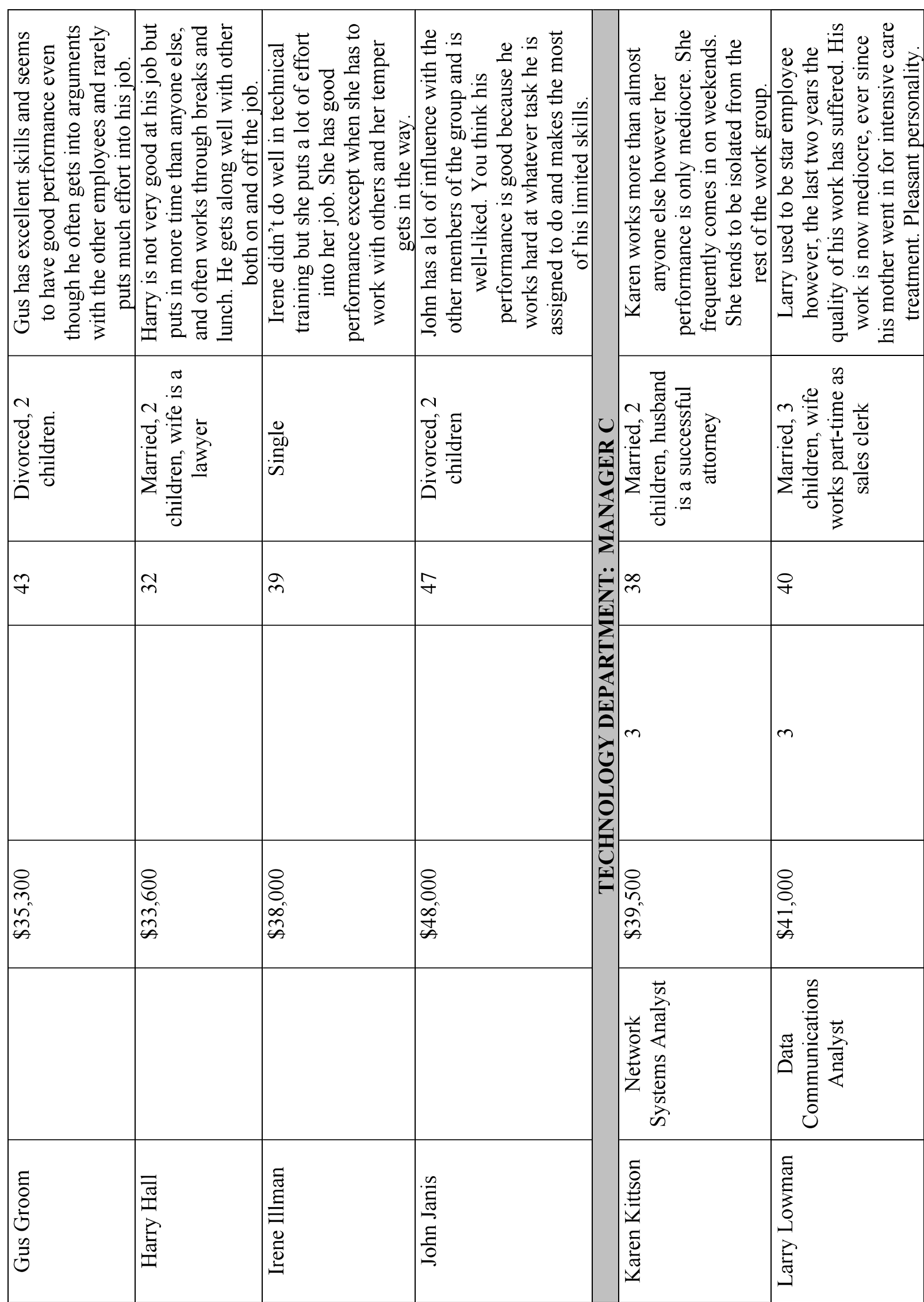




\begin{tabular}{|c|c|c|}
\hline 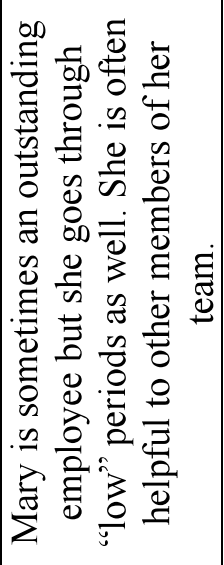 & 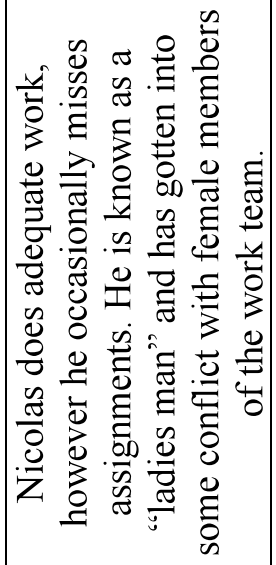 & 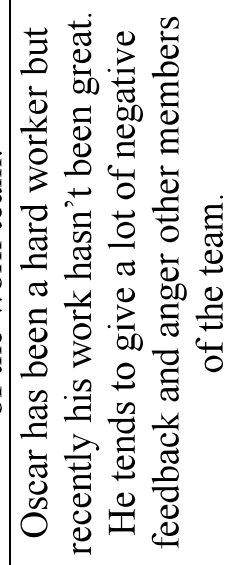 \\
\hline $\begin{array}{l}\frac{0}{00} \\
\stackrel{\Xi}{\infty}\end{array}$ & 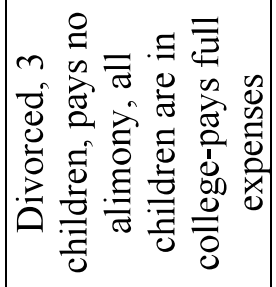 & 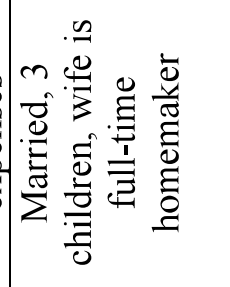 \\
\hline$\stackrel{g}{f}$ & $n$ & 涫 \\
\hline ナ & $m$ & $\sim$ \\
\hline $\begin{array}{l}8 \\
8 \\
\text { \& } \\
\infty\end{array}$ & $\begin{array}{l}8 \\
8 \\
0 \\
0 \\
+ \\
\infty\end{array}$ & $\begin{array}{l}8 \\
\infty \\
\infty \\
\infty \\
n \\
\infty\end{array}$ \\
\hline 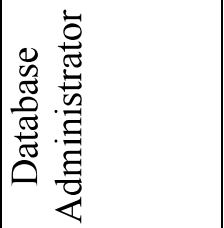 & 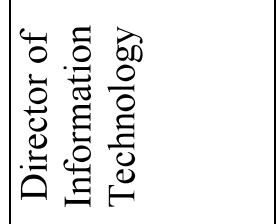 & 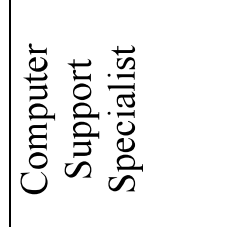 \\
\hline 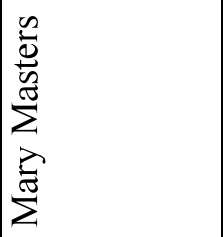 & 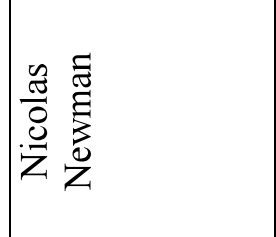 & 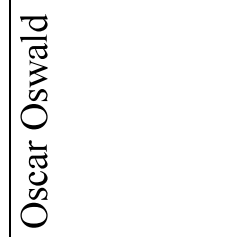 \\
\hline
\end{tabular}

